ISSN 2078-5097. Вісн. Львів. ун-ту. Сер. прикл. матем. та інф. 2018. Вип. 26. С. 56-69

Visnyk of the Lviv University. Series Appl. Math. and Informatics. Issue 26. P. 56-69

УДК 519.632 .4

\title{
ELEMENTWISE DECOMPOSITION OF A POSTERIORI ERROR ESTIMATOR BASED ON REFERENCE SOLUTION FOR HP-ADAPTIVE FINITE ELEMENT METHOD
}

\author{
R. Drebotiy ${ }^{1}$, H. Shynkarenko ${ }^{1,2}$ \\ ${ }^{I}$ Ivan Franko National University of Lviv, \\ Universytetska Str., 1, Lviv, 79000, e-mail: roman.drebotiy@gmail.com, \\ ${ }^{2}$ Polytechnica Opolska, Opole,Poland, e-mail: h.shynkarenko@po.opole.pl
}

\begin{abstract}
We consider the construction of a posteriori error estimator (AEE), based on the reference solution for one-dimensional $h p$-adaptive finite element method (FEM). It is shown that the square of the global error estimator can be represented as a sum of squares of single element error indicators, which are calculated independently on the elements of the selected mesh. The obtained decomposition can be used to justify the iterative algorithms of $h p$-adaptive FEM schemes. The proposed estimator can be used to calculate the error decrease rates for different local mesh refinement of just single finite element without re-calculating the entire reference solution on the whole problem domain. In addition, by choosing the system of Lobatto functions as a finite element basis, we propose an efficient scheme for calculating the local indicators.
\end{abstract}

Key words: finite element method, Galerkin method, orthogonal projection, Lobatto basis, Green's function, $h p$-adaptivity, a posteriori error estimator, well posed problem, diffusion-advection-reaction boundary value problem, reference solution.

\section{INTRODUCTION}

Adaptive finite element schemes are one of the most commonly used in practice algorithms for discretization of boundary value problems for both ordinary differential equations and partial differential equations [2,3,9]. The key problem in constructing such schemes is a reliable estimate of the error of the approximation found on each finite element. The distribution of values of the obtained estimates allow us to find the regions of the solution's domain of definition with the increased level of error and, in turn, carry out the local refinement of the mesh in these regions in order to achieve the given accuracy of approximation with the most economical use of computing resources [1, 2, 4-6, 13, 14]. In addition to the above-mentioned local coarsening/refinement of a finite element mesh at each adaptation step ( $h$-adaptivity), we can also increase the order of polynomial approximations on selected elements with higher levels of error ( $p$-adaptivity) [13, 10-12]. The combination of the described adaptation options is the basis of the so-called $h p$ adaptive FEM schemes [4-6, 10-14]. The latter, giving a greater freedom to construct the approximation spaces, introduces a complex problem of optimal choice between the local spatial refinement of a mesh and/or an increasing the order of the basis functions on finite elements $[4,13]$. Successful resolution of this optimization problem requires, in particular, the construction of error estimates for high order approximations, which will allow a certain homogenity of computational procedures to be achieved on finite elements. However, the difficulty in solving these problems can be compensated by the potentially exponential convergence of the calculated sequence of finite-element approximations [10-12].

In this article, we consider a posteriori error estimator, based on the reference solution, which can be used regardless of the type of boundary value problem, the order of

(C) Drebotiy R., Shynkarenko H., 2018 
R. Drebotiy, H. Shynkarenko

approximation and the dimension of the problem domain of definition. Such estimator can be seen in the fundamental papers of Demkowicz [4] and Sorlın [14]. It was used there to construct automated software packages for engineering computations using $h p$-adaptive finite element method. It should be noted that in these works there are local error indicators considered without a strict justification of the overall error estimator across the entire problem domain. The latter requires the establishment of a certain link between the global estimator of the error and the distribution of its local indicators, which is the main purpose of this article.

For an one-dimensional case, it will further be proved that the square of the considered AEE, determined on the whole domain of the problem, is equal to the sum of squares of the same estimators, but calculated separately and independently on each finite element. We provide further exploration of the established fact and alternative proof of it, which is based on a more general considerations using Green's function. For onedimensional space, such AEEs are used to estimate the approximation of the FEM approximation for convection-diffusion-reaction problems (which, in fact, are the most general linear problems in this case):

$$
\begin{aligned}
& \text { given coefficients of diffusion } \mu=\mu(x) \text {, convection } \beta \\
& \text { reaction } \sigma=\sigma(x), \text { and sources } f=f(x) \\
& \quad \text { and numbers } \alpha, \gamma, g_{0}, g_{L} \in \mathbb{R} ; \\
& \text { find function } u=u(x), \text { such that } \\
& \qquad A u \equiv-\left(\mu u^{\prime}\right)^{\prime}+\beta u^{\prime}+\sigma u=f \quad \text { on } \Omega=(0, L), \\
& \qquad\left.\mu u^{\prime}\right|_{x=0}=\alpha\left[u(0)-g_{0}\right],-\left.\mu u^{\prime}\right|_{x=L}=\gamma\left[u(L)-g_{L}\right] .
\end{aligned}
$$

Problem (1) admits the following variational formulation:

$$
\left\{\begin{array}{c}
\text { find function } u \in V:=H^{1}(\Omega) \text {, such that } \\
c_{\Omega}(u, v)=\left\langle l_{\Omega}, v\right\rangle \quad \forall v \in V,
\end{array}\right.
$$

where

$$
\begin{array}{rr}
c_{\Omega}(u, v):=\left(\mu u^{\prime}, v^{\prime}\right)+\left(\beta u^{\prime}, v\right)+(\sigma u, v) & \\
+\left.\alpha u v\right|_{x=0}+\left.\gamma u v\right|_{x=L} & \forall u, v \in V, \\
\left\langle l_{\Omega}, v\right\rangle:=(f, v)+\alpha g_{0} v(0)+\gamma g_{L} v(L) \quad & \forall v \in V .
\end{array}
$$

Here

$$
(f, v):=\int_{\Omega} f(x) v(x) d x \quad \forall f, v \in L^{2}(\Omega) .
$$

We assume that the data of considered problem (1) guarantee the variational formulation is (2) well-posed.

General purpose of $h p$-adaptive FEM algorithms is to build the sequence of finitedimensional piecewise-polynomial approximation spaces $\left\{V_{h p}\right\}, V_{h p} \subset V, \operatorname{dim} V_{h p}<+\infty$, which allows you to compute the sequence of convergent approximations i.e.

find approximation $u_{h p} \in V_{h p}$, such that $c_{\Omega}\left(u_{h p}, v\right)=\left\langle l_{\Omega}, v\right\rangle \quad \forall v \in V_{h p}$.

With a given value of the tolerance parameter $t o l>0$ the algorithm should guarantee fulfillment of the criteria

$$
\left\|u-u_{h p}\right\|_{V} \leq t o l
$$

with the least computational cost. Here 


$$
\|v\|_{V}=\sqrt{c_{\Omega}(v, v)}
$$

is the energy norm of the variational problem (2).

As it was mentioned in the beginning, in this article we will study the specific a posteriori error estimator and will concentrate our attention on the computational scheme for it. The structure of this article is as follows: in section 2 the general definition of the error estimator, based on the reference solution, is provided; in section 3 the scheme of calculation of the estimator is provided and we discuss aspects of its effective implementation; in section 4 the main theorem on the representation of a global AEE, based on the reference solution, in the form of the sum of the squares of the corresponding local indicators is proved; in section 5 we further explore the problem of estimator decomposition and consider alternative proof of the main theorem based on more general criteria.

\section{A POSTERIORI ERROR ESTIMATOR BASED ON REFERENCE SOLUTION}

Let us consider the mesh $\mathrm{X}=\left\{x_{i}\right\}_{i=0}^{N}, \quad 0=x_{0}<x_{1}<\ldots<x_{N}=L$, denote $h_{i}=x_{i}-x_{i-1}, i=1, \ldots, N$, and introduce the finite element partition $\mathfrak{J}_{h}=\left\{\left(x_{i-1}, x_{i}\right)\right\}_{i=1}^{N}$. We assume, that on each finite element $K=\left(x_{i-1}, x_{i}\right)$ space $X_{p_{K}}(K)$ of all possible polynomials, degree of which does not exceed $p_{K}$ is constructed (we will also use the notation $\left.p_{i}:=p_{K}\right)$. We define vectors $h=\left(h_{1}, h_{2}, \ldots, h_{N}\right)$ and $p=\left(p_{1}, p_{2}, \ldots, p_{N}\right)$, that uniquely define a mesh of finite elements and polynomial degrees of approximations on the corresponding elements. Now we can define the space of approximations on the entire problem domain of definition

$$
X_{h, p}(\Omega)=\left\{v \in C(\Omega)|v|_{K} \in X_{p_{K}}(K), K=\left(x_{i-1}, x_{i}\right), i=1, \ldots, N\right\} .
$$

Let us construct finite element approximation $u_{h, p} \in X_{h, p}(\Omega)$ for problem (2). Define operation $\mathbb{R}^{N} \ni\left(v_{1}, v_{2}, \ldots, v_{N}\right)=v \mapsto \mathbf{v}=\left(v_{1}, v_{1}, v_{2}, v_{2}, \ldots, v_{N}, v_{N}\right) \in \mathbb{R}^{2 N}$. Let us also assume that if we have defined the vector $v=\left(v_{1}, v_{2}, \ldots, v_{N}\right)$, then denote $v+1:=\left(v_{1}+1, v_{2}+1, \ldots, v_{N}+1\right)$. Consider a global estimator $\eta_{\Omega}$ that is calculated as a certain distance between the current approximation $u_{h, p}$ and another approximation $u_{\mathbf{h} / 2, \mathbf{p}+1} \in X_{\mathbf{h} / 2, \mathbf{p}+1}(\Omega)$. Let us recall that mesh defined by the pair $(\mathbf{h} / 2, \mathbf{p}+1)$ is obtained from mesh $(h, p)$ by applying uniform bisection and increasing by 1 approximation order on each new sub-element. We will use the following formula to compute the estimator:

$$
\eta_{\Omega}=\left\|u_{\mathbf{h} / 2, \mathbf{p}+1}-u_{h, p}\right\|_{H^{1}(\Omega)}=\sqrt{\sum_{K} \eta_{K}^{2}},
$$

where local indicators $\eta_{K}$ are computed as:

$$
\eta_{K}=\left\|u_{\mathbf{h} / 2, \mathbf{p}+1}-u_{h, p}\right\|_{H^{1}(K)} .
$$

Approximation $u_{\mathbf{h} / 2, \mathbf{p}+1}$ we will call reference solution $[4,14]$.

Considered a posteriori estimates has advantage over other estimates because it can be used regardless of the adaptation scheme and/or boundary value problem or mesh structure. On the other hand, in the context of $h p$-adaptation algorithms we need to compare different refinement patterns on each finite element. Such comparison is done by comparing 
R. Drebotiy, H. Shynkarenko

the error estimates for different refinements. Thus, if we want to proceed with such technique and use indicator (8), we will need to calculate estimate

$$
\eta_{K}^{\text {new }}=\left\|u_{\mathbf{h} / 2, \mathbf{p}+1}-u_{h^{\prime}, p^{\prime}}\right\|_{H^{1}(K)},
$$

where mesh defined by $\left(h^{\prime}, p^{\prime}\right)$ is obtained from current mesh by refinement of single element $K$. In this case it is not possible to find $\eta_{K}^{\text {new }}$ efficiently, without calculating approximation $u_{h^{\prime}, p^{\prime}}$ on entire domain. Taking into account that we have many elements and on each of them we should compare different refinements, we can conclude that obtained estimate is not efficient. To improve indicator $\eta_{K}$, in $[4,14]$ it is proposed to modify (8) in such way that for fixed reference solution we will calculate its projection onto the current mesh rather than direct FEM approximation:

$$
\tilde{\eta}_{K}=\left|u_{\mathbf{h} / 2, \mathbf{p}+1}-\prod_{h, p}^{K} u_{\mathbf{h} / 2, \mathbf{p}+1}\right|_{H^{1}(K)},
$$

where $|\cdot|_{H^{1}(K)}$ is defined as:

$$
|w|_{H^{1}(K)}^{2}=\int_{K}\left(w^{\prime}\right)^{2} \mathrm{dx} \quad \forall w \in H^{1}(K),
$$

$\prod_{h, p}^{K}: H^{1}(K) \rightarrow X_{p_{K}}(K)$ is an orthogonal projection operator onto the mesh defined by the pair $(h, p)$. Introduced projector is constructed later in (12).

We can compute the same estimator on the entire domain:

$$
\tilde{\eta}_{\Omega}=\left|u_{\mathbf{h} / 2, \mathbf{p}+1}-\prod_{h, p}^{\Omega} u_{\mathbf{h} / 2, \mathbf{p}+1}\right|_{H^{1}(\Omega)} .
$$

In this article we study the relation between quantities of the estimator $\tilde{\eta}_{\Omega}$ and indicators $\tilde{\eta}_{K}$.

\section{PROJECTIONS OF THE REFERENCE SOLUTION AND THEIR EFFICIENT COMPUTATION}

Let now describe a construction of the projector, mentioned above. Without loss of generality, we will proceed with projection on the entire domain $\Omega$. In the completely same manner, we can find a projection on the single element $K$ or even on every other interval. For every function $w \in H^{1}(\Omega)$ its orthogonal projection $w_{h, p}=\prod_{h, p}^{\Omega} w$ is defined as follows:

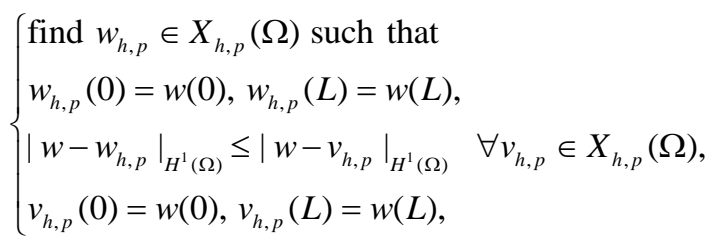

or using the next definition, which is equivalent to (12): 


$$
\left\{\begin{array}{l}
\text { find } w_{h, p} \in X_{h, p}(\Omega) \text { such that } \\
w_{h, p}(0)=w(0), w_{h, p}(L)=w(L), \\
\int_{\Omega}\left(w_{h, p}^{\prime}-w^{\prime}\right) v^{\prime} \mathrm{dx}=0, \quad \forall v \in X_{h, p}(\Omega), \\
v(0)=v(L)=0 .
\end{array}\right.
$$

Consider now the general scheme of computation of projection, which is defined by (13). In space $X_{h, p}(\Omega)$ we choose Lobatto basis $\left\{\varphi_{j}\right\}_{j=0}^{M}$ of the following kind [4, 14]:

$$
\begin{aligned}
& \varphi_{0}(x)=1-\frac{x}{L}, \quad \varphi_{1}(x)=\frac{x}{L}, \\
& \varphi_{n}(x)=\int_{-1}^{2 x / L-1} l_{n-1}(t) \mathrm{dt}, n=2, \ldots, M,
\end{aligned}
$$

where $l_{n-1}:[-1,1] \rightarrow \mathbb{R}$ is a Legendre polynomial of degree $n-1$.

It should be noted that computing the values of basis functions $\varphi_{n}$ directly by the given formula (14) is inefficient. For a more effective formula, let's consider the known Legendre equation

$$
\left[\left(t^{2}-1\right) l_{n}^{\prime}(t)\right]^{\prime}=n(n+1) l_{n}(t), t \in[-1,1] .
$$

By substituting $n-1$ instead of $n$ and integrating (15) on a segment $[-1,2 x / L-1]$ we will obtain an alternative representation of the basis bubble functions:

$$
\varphi_{n}(x)=\left((2 x / L-1)^{2}-1\right) \cdot \frac{1}{n(n-1)} l_{n-1}^{\prime}(2 x / L-1), \quad n=2, \ldots, M .
$$

Differentiation of (16) brings us to similar formula for derivatives $\varphi_{n}^{\prime}, n=2, . ., M$ :

$$
\varphi_{n}^{\prime}(x)=\frac{2}{n(n-1) L}\left[(2 x / L-1) l_{n-1}^{\prime}(2 x / L-1)+\left((2 x / L-1)^{2}-1\right) l_{n-1}^{\prime \prime}(2 x / L-1)\right] \text {. }
$$

Now, using the linear recurrence relation (18) for Legendre polynomials (see recurrence equations for orthogonal polynomials in $[7,8]$ )

$$
l_{n+1}(t)=t l_{n}(t)-\frac{n^{2}}{4 n^{2}-1} l_{n-1}(t), \quad n \geq 1
$$

it is not hard to construct an appropriate recurrence relations for derivatives of these polynomials by using simple differentiation of (18):

$$
\begin{aligned}
& l_{n+1}^{\prime}(t)=l_{n}(t)+t l_{n}^{\prime}(t)-\frac{n^{2}}{4 n^{2}-1} l_{n-1}^{\prime}(t), \quad n \geq 1, \\
& l_{n+1}^{\prime \prime}(t)=2 l_{n}^{\prime}(t)+t l_{n}^{\prime \prime}(t)-\frac{n^{2}}{4 n^{2}-1} l_{n-1}^{\prime \prime}(t), \quad n \geq 1 .
\end{aligned}
$$

Now we can calculate the values of functions $\varphi_{n}, \varphi_{n}^{\prime}, \quad n=2, \ldots, M$ by using obtained recurrence relations (18) and (19) and combining them with formulas (16) and (17).

Now to solve the problem (13) we present the projection $w_{h, p}(x)$ in the form

$$
w_{h, p}(x)=w(0) \varphi_{0}(x)+w(L) \varphi_{1}(x)+\sum_{j=2}^{M} q_{j} \varphi_{j}(x),
$$


and by using Galerkin procedure we can find coefficients $q_{j}$ as the solution of the system of the linear algebraic equations (or simply, linear system):

$$
\sum_{j=2}^{M} q_{j} \int_{\Omega} \varphi_{j}^{\prime} \varphi_{i}^{\prime} \mathrm{dx}=\int_{\Omega}\left(w^{\prime}-w(0) \varphi_{0}^{\prime}-w(L) \varphi_{1}^{\prime}\right) \varphi_{i}^{\prime} \mathrm{dx}, \quad i=2, \ldots, M .
$$

Taking into account the structure of the Lobatto basis functions (14) and the orthogonality of the Legendre polynomials, we can see, that the matrix of system (21) is diagonal, what makes the calculation of the projection a trivial problem.

Now, since the function $u_{\mathbf{h} / 2, \mathbf{p}+1}$ is a polynomial and having a polynomial $\prod_{h, p}^{K} u_{\mathbf{h} / 2, \mathbf{p}+1}$ we can accurately calculate the value of the error

$$
\left|u_{\mathbf{h} / 2, \mathbf{p}+1}-\prod_{h, p}^{K} u_{\mathbf{h} / 2, \mathbf{p}+1}\right|_{H^{1}(K)}=\sqrt{\int_{K}\left(u_{\mathbf{h} / 2, \mathbf{p}+1}^{\prime}-\left(\prod_{h, p}^{K} u_{\mathbf{h} / 2, \mathbf{p}+1}\right)^{\prime}\right)^{2} \mathrm{dx}}
$$

on each finite element, for example, by the Gaussian quadrature formulas [7, 8].

\section{DECOMPOSITION OF THE A POSTERIORI ERROR ESTIMATOR}

In this section we present the base proof of the theorem on the decomposition of AEE (11) based on the reference solution. Next, we prove an auxiliary criteria that provides sufficient condition for the approximation of the FEM to be an interpolation function for the exact solution on the considered set of mesh nodes. On the basis of the proven criteria, an alternative proof of Theorem 1 is constructed.

Theorem 1. (on the decomposition of AEE based on the reference solution).

Let us consider the finite element partition

$$
\mathfrak{J}_{h}=\left\{\left(x_{i-1}, x_{i}\right)\right\}_{i=1}^{N},
$$

where $0=x_{0}<x_{1}<\ldots<x_{N}=L$ and $\Omega=(0, L)$. Next, we define high-order finite element approximation space

$$
X_{h, p}(\Omega)=\left\{v \in C(\Omega)|v|_{K} \in X_{p_{K}}(K), K=\left(x_{i-1}, x_{i}\right), i=1, \ldots, N\right\},
$$

where $X_{p_{K}}(K)$ is the local approximation space on element $K$ with polynomial order $p_{K}$. On arbitrary interval $D=(\alpha, \beta) \subset \Omega$ consider the operator of orthogonal projection

$$
\begin{gathered}
\prod_{h, p}^{D}: H^{1}(D) \rightarrow X_{h, p}(D), \\
X_{h, p}(D)=\left\{v\left|\exists u \in X_{h, p}(\Omega): v=u\right|_{D}\right\},
\end{gathered}
$$

defined in (13) in respect to seminorm $|\cdot|_{H^{1}(D)}$.

For an arbitrary function $w \in H^{1}(\Omega)$ the following equality holds:

$$
\left|w-\prod_{h, p}^{\Omega} w\right|_{H^{1}(\Omega)}^{2}=\sum_{K \in \mathfrak{I}_{h}}\left|w-\prod_{h, p}^{K} w\right|_{H^{1}(K)}^{2},
$$

and therefore

$$
\tilde{\eta}_{\Omega}^{2}=\sum_{K \in \mathfrak{I}_{h}} \tilde{\eta}_{K}^{2}
$$

where indicators $\tilde{\eta}_{K}$ and $\tilde{\eta}_{\Omega}$ are defined in (9) and (11) respectively. 
Proof. Consider the space $X_{h, p}(\Omega)$. Let us construct local Lobatto basis in the form of (14) on each finite element. Global basis on domain $\Omega$ will contain nodal functions $\phi_{j}$ and bubble functions $\psi_{i}$. We will show that for an arbitrary function $w \in H^{1}(\Omega)$, its projection

$$
w_{h, p}=\prod_{h, p}^{\Omega} w
$$

is an interpolation function for $w$ in respect to the node system

$$
\mathcal{J}=\left\{x_{i}\right\}_{i=0}^{N},
$$

i. e. $w_{h, p}\left(x_{j}\right)=w\left(x_{j}\right)$. Obviously, for the boundary nodes, the latter equality holds (this follows directly from the definition of the projection). Let us construct global linear system for finding projection. Substituting into equality

$$
\int_{\Omega}\left(w_{h, p}^{\prime}-w^{\prime}\right) v^{\prime} \mathrm{dx}=0
$$

instead of $v$ nodal function $\phi_{j}$, which corresponds to the internal node of the mesh, we get:

$$
\begin{aligned}
\int_{0}^{L} w_{h, p}^{\prime} \phi_{j}^{\prime} \mathrm{dx} & =\int_{x_{j-1}}^{x_{j+1}} w_{h, p}^{\prime} \phi_{j}^{\prime} \mathrm{dx}= \\
& =\int_{x_{j-1}}^{x_{j}} w_{h, p}^{\prime} \phi_{j}^{\prime} \mathrm{dx}+\int_{x_{j}}^{x_{j+1}} w_{h, p}^{\prime} \phi_{j}^{\prime} \mathrm{dx}= \\
& =\frac{1}{h_{j}} \int_{x_{j-1}}^{x_{j}} w_{h, p}^{\prime} \mathrm{dx}-\frac{1}{h_{j+1}} \int_{x_{j}}^{x_{j+1}} w_{h, p}^{\prime} \mathrm{dx}= \\
& =\left.\frac{1}{h_{j}} w_{h, p}\right|_{x_{j-1}} ^{x_{j}}-\left.\frac{1}{h_{j+1}} w_{h, p}\right|_{x_{j}} ^{x_{j+1}}= \\
& =-\frac{1}{h_{j}} w_{h, p}\left(x_{j-1}\right)+\left(\frac{1}{h_{j}}+\frac{1}{h_{j+1}}\right) w_{h, p}\left(x_{j}\right)-\frac{1}{h_{j+1}} w_{h, p}\left(x_{j+1}\right)= \\
& =\int_{0}^{L} w^{\prime} \phi_{j}^{\prime} \mathrm{dx}, \quad j=1, \ldots, N-1 .
\end{aligned}
$$

Let us now consider an arbitrary bubble function $\psi_{i}$ and take into account, that by definition its support does not cross single element boundaries. Moreover

$$
\operatorname{supp}\left(\psi_{i}\right)=\overline{\tilde{K}}=\left[x_{j-1}, x_{j}\right],
$$

where $\tilde{K}$ is some finite element, for which $\psi_{i}$ is also its local basis function.

Obviously, for the restriction of $w_{h, p}$ onto the element $\tilde{K}$ we have:

$$
\left.w_{h, p}\right|_{\tilde{K}}=w_{h, p}\left(x_{j-1}\right) \phi_{j-1}+w_{h, p}\left(x_{j}\right) \phi_{j}+\sum_{\tilde{K}: \operatorname{supp}\left(\psi_{s}\right)=\overline{\tilde{K}}} q_{s} \psi_{s} .
$$

Substituting $\psi_{i}$ into (25) we get: 


$$
\begin{aligned}
\int_{0}^{L} w_{h, p}^{\prime} \psi_{i}^{\prime} \mathrm{dx} & =\int_{\tilde{K}} w_{h, p}^{\prime} \psi_{i}^{\prime} \mathrm{dx}= \\
& =\int_{\tilde{K}}\left[w_{h, p}\left(x_{j-1}\right) \phi_{j-1}+w_{h, p}\left(x_{j}\right) \phi_{j}+\sum_{\tilde{K}: \operatorname{supp}\left(\psi_{s}\right)=\tilde{\tilde{K}}} q_{s} \psi_{s}\right]^{\prime} \psi_{i}^{\prime} \mathrm{dx}= \\
& =\frac{1}{h_{j}}\left[w_{h, p}\left(x_{j}\right)-w_{h, p}\left(x_{j-1}\right)\right] \underbrace{\int_{\tilde{\tilde{K}}}^{\psi_{i}^{\prime}} \mathrm{dx}}_{=0}+\sum_{\tilde{K}: \operatorname{supp}\left(\psi_{s}\right)=\tilde{\tilde{K}}} q_{s} \int_{\tilde{K}} \psi_{s}^{\prime} \psi_{i}^{\prime} \mathrm{dx}= \\
& =\sum_{\tilde{K}: \operatorname{supp}\left(\psi_{s}\right)=\overline{\tilde{K}}} q_{s} \int_{\tilde{K}} \psi_{s}^{\prime} \psi_{i}^{\prime} \mathrm{dx}=\underbrace{L}_{0} w^{\prime} \psi_{i}^{\prime} \mathrm{dx} .
\end{aligned}
$$

In (28) we take into account that $\psi_{i}^{\prime}$ is the Legendre polynomial scaled to $\tilde{K}$ (see (14)) and therefore it is orthogonal to constant, i.e.

$$
\int_{\widetilde{K}} \psi_{i}^{\prime} \mathrm{dx}=\int_{\widetilde{K}} 1 \cdot \psi_{i}^{\prime} \mathrm{dx}=0 .
$$

All equations of global linear system for finding projection are present in (26) and (28). We can also observe that equations (28) do not contain nodal values $w_{h, p}\left(x_{j}\right)$. Thus, for finding nodal values we get the linear system consisting of the values in the boundary nodes from (13) and equations (26).

Similarly, after performing the same transformations, as in (26), but now directly for

$$
\int_{0}^{L} w^{\prime} v^{\prime} \mathrm{dx}
$$

we obtain

$$
-\frac{1}{h_{j}} w\left(x_{j-1}\right)+\left(\frac{1}{h_{j}}+\frac{1}{h_{j+1}}\right) w\left(x_{j}\right)-\frac{1}{h_{j+1}} w\left(x_{j+1}\right)=\int_{0}^{L} w^{\prime} \phi_{j}^{\prime} \mathrm{dx}, j=1, \ldots, N-1 .
$$

By adding to the relations (29) the values $w\left(x_{j}\right)$ in the boundary nodes and comparing them with the previous relations (26) for $w_{h, p}\left(x_{j}\right)$, we see that the values $w_{h, p}\left(x_{j}\right)$ and $w\left(x_{j}\right)$ are solutions of identical linear systems, and therefore they are equal.

Taking into account the above property, we can attach conditions of equality in mesh nodes to the definition of a projection $w_{h, p}$, obtaining the next, equivalent, definition:

$$
\left\{\begin{array}{l}
\text { find } w_{h, p} \in X_{h, p}(\Omega) \text { such that } \\
w_{h, p}\left(x_{j}\right)=w\left(x_{j}\right), j=0, \ldots, N \\
\int_{\Omega}\left(w_{h, p}^{\prime}-w^{\prime}\right) v^{\prime} \mathrm{dx}=0, \quad \forall v \in X_{h, p}(\Omega), \\
v\left(x_{j}\right)=0, j=0, \ldots, N .
\end{array}\right.
$$


Now, taking into account structure of the space $X_{h, p}(\Omega)$, we can obtain a sequence of well-posed variational problems for determining local operators $\prod_{h, p}^{K}$ for finding projections $w_{h, p}=\prod_{h, p}^{K} w$ on each finite element $K=\left(x_{j-1}, x_{j}\right), j=0, \ldots, N$ :

$$
\left\{\begin{array}{l}
\text { find } w_{h, p} \in X_{p_{K}}(K) \text { such that } \\
w_{h, p}\left(x_{j-1}\right)=w\left(x_{j-1}\right), w_{h, p}\left(x_{j}\right)=w\left(x_{j}\right) \\
\int_{K}\left(w_{h, p}^{\prime}-w^{\prime}\right) v^{\prime} \mathrm{dx}=0, \forall v \in X_{p_{K}}(K), \\
v\left(x_{j-1}\right)=v\left(x_{j}\right)=0 .
\end{array}\right.
$$

From (30) we get, that $\left(\prod_{h, p}^{K} w\right)(x)=\left(\prod_{h, p}^{\Omega} w\right)(x), x \in K=\left(x_{i-1}, x_{i}\right), i=0, \ldots, N$. Now we can obtain equality (23) using simple transformations:

$$
\begin{aligned}
& \left|w-\prod_{h, p}^{\Omega} w\right|_{H^{1}(\Omega)}^{2}=\int_{\Omega}\left(w-\prod_{h, p}^{\Omega} w\right)^{2} \mathrm{dx} \\
& =\sum_{K \in \mathfrak{I}_{h}} \int_{K}\left(w-\prod_{h, p}^{\Omega} w\right)^{2} \mathrm{dx}=\sum_{K \in \mathfrak{I}_{h}} \int_{K}\left(w-\prod_{h, p}^{K} w\right)^{2} \mathrm{dx} \\
& =\sum_{K \in \mathfrak{I}_{h}}\left|w-\prod_{h, p}^{K} w\right|_{H^{1}(K)}^{2} .
\end{aligned}
$$

Equality (24) is obtained from (23) by taking $w:=u_{\mathbf{h} / 2, \mathbf{p}+1}$. Each of the problems of the resulting sequence (30) is directly reduced to the linear system of the form (21).

\section{ALTERNATIVE PROOF OF THE THEOREM 1 BASED ON THE GREEN'S FUNCTION}

Analyzing the last proof, we see that it is based on the proven fact of equality of projection and projected function in the nodes of the selected mesh. Consider the alternative proof of this fact, based on more general considerations. First, we prove the assertion:

Theorem 2. (on the finite element approximation in mesh nodes).

Let us consider Dirichlet boundary value problem on the domain $\bar{\Omega}=[0, L]$ for a linear second-order differential equation $A u=f$ with sufficiently smooth data. Consider also approximation $u_{h} \in u_{0}+V_{h}, u_{0} \in H^{1}(\Omega), V_{h} \subset H_{0}^{1}(\Omega), \operatorname{dim} V_{h}<+\infty$, obtained using Galerkin method (in the standard way, with reduction of the original problem to a problem with homogeneous boundary conditions). If for the Green's function $G(x, s)$ of the corresponding boundary value problem with homogeneous boundary conditions at a point $x_{0} \in \Omega$ the following condition holds:

$$
G\left(x_{0}, \cdot\right) \in V_{h},
$$

then $u_{h}\left(x_{0}\right)=u\left(x_{0}\right)$.

Proof. Choose a function $u_{0} \in H^{1}(\Omega)$ that satisfies the boundary conditions of the problem. Thus, the original problem is reduced to finding a function $\tilde{u} \in H_{0}^{1}(\Omega)$ that is a solution of the equation $L \tilde{u}=g$ where $g=f-L u_{0}$. An approximation of the solution of 
the original problem will be computed in the form $u_{h}=u_{0}+\tilde{u}_{h}$ where $\tilde{u}_{h}$ is a Galerkin approximation of the corresponding problem with homogeneous boundary conditions. We denote, for simplicity, $(u, v)=(u, v)_{L^{2}(\Omega)}$. Obviously that

$$
(L \tilde{u}, v)=(g, v), \forall v \in H_{0}^{1}(\Omega) \text {. }
$$

Since $\tilde{u} \in H_{0}^{1}(\Omega)$, then also

$$
\left(L \tilde{u}_{h}, v_{h}\right)=\left(g, v_{h}\right), \forall v_{h} \in V_{h} .
$$

From the properties of the Green's function and the form of the equation, we obtain

$$
\tilde{u}(x)=(G(x, \cdot), g)=(L \tilde{u}, G(x, \cdot)) .
$$

Obviously, the error $\tilde{e}=\tilde{u}-\tilde{u}_{h} \in H_{0}^{1}(\Omega)$ also satisfies the homogeneous Dirichlet boundary conditions and it is the solution of the equation $L \tilde{e}=g-L \tilde{u}_{h}$. Taking into account that the Green's function does not depend on the right-hand side of the equation, we obtain by analogy with (34):

$$
\tilde{e}(x)=(L \tilde{e}, G(x, \cdot)) .
$$

Now by subtracting the equality (32) (at $v \in V_{h}$ ) and (33) we obtain, in essence, the Galerkin orthogonality condition:

$$
\left(L \tilde{e}, v_{h}\right)=0, \forall v_{h} \in V_{h} .
$$

Comparing (35) and (36) we see that if $G\left(x_{0}, \cdot\right) \in V_{h}$ for some point $x_{0} \in \Omega$, then $\tilde{e}\left(x_{0}\right)=0$. Now, it is not difficult to obtain the assertion of the theorem: $\left(u-u_{h}\right)\left(x_{0}\right)=\left(\left(u-u_{0}\right)-\left(u_{h}-u_{0}\right)\right)\left(x_{0}\right)=\tilde{e}\left(x_{0}\right)=0$.

Corollary 1. (alternative proof of accuracy of the projection in the mesh nodes). Consider the problem (13). It is obvious that it is a discrete problem of the Galerkin method for the corresponding boundary value problem:

$$
\left\{\begin{array}{l}
\text { find } w \in C^{2}(\Omega), \text { such that } \\
-w^{\prime \prime}=q, \\
w(0)=u(0), w(L)=u(L),
\end{array}\right.
$$

where $q=-u^{\prime \prime}$. The exact solution of the last problem is $w=u$. Let us find the Green's function of the corresponding problem with homogeneous boundary conditions:

$$
\left\{\begin{array}{l}
\text { find } w \in C^{2}(\Omega), \text { such that } \\
-w^{\prime \prime}=q, \\
w(0)=w(L)=0 .
\end{array}\right.
$$

From the definition of Green's function we obtain that

$$
\left\{\begin{array}{l}
-G_{x x}^{\prime \prime}(x, s)=\delta(x-s),(x, s) \in \Omega^{2}, \\
G(0, s)=G(L, s)=0,
\end{array}\right.
$$

where $\delta$ is a Dirac $\delta$-function. Now we fix an arbitrary point $s \in \Omega$. Consider the decomposition:

$$
G(x, s)= \begin{cases}G_{l}(x, s), & x \leq s, \\ G_{r}(x, s), & x>s .\end{cases}
$$

Integrating equation from (39) on $x \in[s-\varepsilon, s+\varepsilon], \varepsilon>0$ brings us to:

$$
G_{x}^{\prime}(s-\varepsilon, s)-G_{x}^{\prime}(s+\varepsilon, s)=1 .
$$


Passing formally $\varepsilon \rightarrow 0$ in (41), we obtain a relation that is postulated additionally in the classical definition of the Green's function:

$$
G_{x}^{\prime}(s-0, s)-G_{x}^{\prime}(s+0, s)=1 .
$$

Taking into account (40):

$$
\left(G_{l}\right)_{x}^{\prime}(s-0, s)-\left(G_{r}\right)_{x}^{\prime}(s+0, s)=1 .
$$

In addition, it should be noted, that from the continuity of the Green's function we obtain:

$$
G_{l}(s, s)=G_{r}(s, s) .
$$
following:

In addition to the last equality by a combination of (39) and (40) we obtain the

$$
\left\{\begin{array}{l}
-\left(G_{l}\right)_{x x}^{\prime \prime}(x, s)=0, x<s, \\
-\left(G_{r}\right)_{x x}^{\prime \prime}(x, s)=0, x>s, \\
G_{l}(0, s)=G_{r}(L, s)=0 .
\end{array}\right.
$$
functions:

From the first two equations (45) we can write a general form of the desired

$$
\left\{\begin{array}{l}
G_{l}(x, s)=x A_{l}(s)+B_{l}(s), \\
G_{r}(x, s)=x A_{r}(s)+B_{r}(s) .
\end{array}\right.
$$

Taking into account the relation (43)-(46), we obtain a system of equations:

$$
\left\{\begin{array}{l}
\text { find functions } A_{l}(s), B_{l}(s), A_{r}(s), B_{r}(s), \text { such that } \\
B_{l}(s)=0 \\
L A_{r}(s)+B_{r}(s)=0 \\
s A_{l}(s)+B_{l}(s)=s A_{r}(s)+B_{r}(s) \\
A_{l}(s)-A_{r}(s)=1
\end{array}\right.
$$

By directly solving the obtained system and taking into account (46) and decomposition (40) we finally get:

$$
G(x, s)= \begin{cases}x\left(1-\frac{s}{L}\right), & x \leq s, \\ s\left(1-\frac{x}{L}\right), & x>s .\end{cases}
$$

We see that formula (48) defines a piecewise-linear function with respect to $x$, for every fixed $s$ with a discontinuity of the derivative at the point $x=s$. Given the symmetry of the Green's function (which, in particular, is easy to see in this particular example), we obtain that for every fixed $x$ function $G(x, s)$ will be a piecewise-linear with respect to $s$, having discontinuity of the derivative at the point $s=x$. Taking into account now the structire of the approximation space of the problem (13), we obviously obtain the condition (31) of Theorem 2 in the mesh nodes $x_{i}$. Hence, in accordance with the scheme of proof of theorem 1, we obtain the possibility of elementwise calculation of the error by solving problems (30). The graph of the function $G(x, s)$ with fixed $s$ is depicted in Fig. 1. 


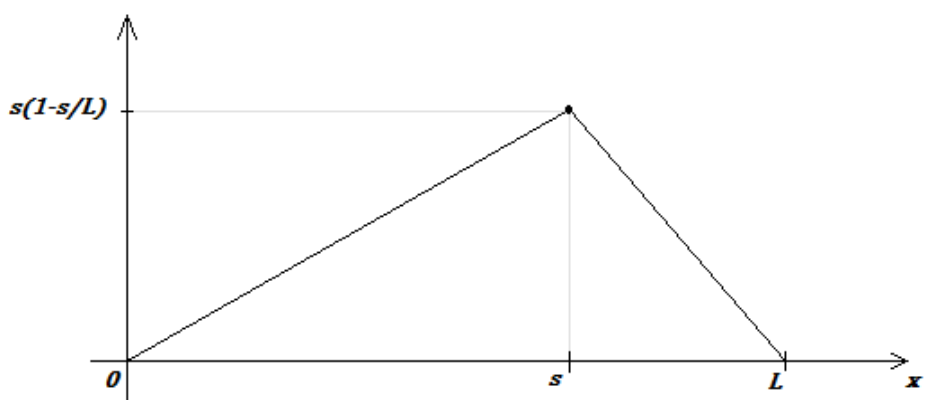

Fig. 1. The graph of the function $G(x, s)$ with fixed $s$

\section{CONCLUSION}

We consider the construction of a posteriori error estimator based on the reference solution which was proposed in the papers of Demkowicz [4] and Sǒlın [14] for the onedimensional $h p$-adaptive finite element method schemes. Using the Green's function, it is shown that the square of the constructed global error estimator can be represented by the sum of squares of element-defined indicators, which are independently calculated on the elements of the selected grid. The obtained correlation makes it possible to substantiate the iterative algorithms for solving optimization problems that arise during the construction of the FEM $h p$-adaptive schemes and is a refinement of the results from [4]. The effective scheme of calculation of local indicators is highlighted.

\section{REFERENCES}

1. Абрамов $C$. Кусково-лінійні апроксимації $h$-адаптивного методу скінчених елементів для одновимірних крайових задач / С. Абрамов, О. Ліпіна, Г. Шинкаренко, А. Ямелинець // Вісн. Львів. ун-ту. Сер. прикл. мат. та інформ. 2006. - Вип. 11. - С. 3-18.

2. Ainsworth M. A posteriori error estimators in finite element analysis / M. Ainsworth, J.T. Oden. - New-York: Wiley, 2000. - 240 p.

3. Brenner S. The Mathematical Theory of Finite Element Methods / S. Brenner, L. Scott. - Springer, 2008, 3ed. - 404 p.

4. Demkowicz L. Computing with $h p$-adaptive finite elements. I One- and Two Dimensional Elliptic and Maxwell Problems / L. Demkowicz. - Austin, 2005. - 389 p.

5. Drebotiy $R$. Comparison of error indicators and refinement criteria for $h p$-adaptation algorithm for finite element method / R. Drebotiy, H. Shynkarenko // Visnyk Odeskoho Natsionalnoho Universytetu. Matematyka i Mekhanika, Odessa, 2014. - Vol. 19, Is. 4 (24). -P. 45-57.

6. Drebotiy $R$. $h p$-adaptive finite element method for $1 \mathrm{~d}$ diffusion-convection-reaction boundary value problems / R. Drebotiy, H. Shynkarenko // Manufacturing Processes. Actual Problems-2014. - Politechnika Opolska, Opole. - 2014. - Vol. 1. - P. 11-26.

7. Golub G. Calculation of Gaussian quadrature rules / G. Golub, J. Welsch // American Mathematical Society, Mathematics of Computation. - 1969. - Vol. 23, No. 106. - 221230.

8. Krylov V.I. Approximate calculation of integrals / V.I. Krylov. - New-York, Mineola, Dover Publications, 2005. - 360 p. 
9. $\operatorname{Logg}$ A. Automating the Finite Element Method / A. Logg // University of Chicago Press, Sixth Winter School in Computational Mathematics, Geilo, March 5-10.2006. -90 p.

10. Melenk J.M. A posteriori error analysis of $h p$-FEM for singularly perturbed problems / J.M. Melenk, T.P. Wihler // Swiss National Science Foundation. - 2014.

11. Melenk J.M. hp-finite element methods for singular perturbations / J.M. Melenk. Springer, Berlin 2002. -317 p.

12. Melenk J.M. On robust exponential convergence of $h p$-finite element methods for problems with boundary layers / J.M. Melenk // ETH Zürich. - 1996.

13. Schwab Ch. p and hp-Finite Element Methods / Ch. Schwab // Oxford: Clarendon Press, 1998. - $386 \mathrm{p}$.

14. Sǒlín P. Higher-Order Finite Element Methods / P. Sǒlín, K. Segeth, I. Dolezel. London: Chapman \& Hall, 2003. - 408 p.

15. Sólín P. Static Condensation, Partial Orthogonalization of Basis Functions, and ILU Preconditioning in the $h p$-FEM / P. Sǒlín, T. Vejchodsky // The University of Texas at El Paso, Department of Mathematical Sciences Research Reports Series, Research Report. -2007. - No. 4.

Стаття: надійшла до редколегї 28.08.2018

доопраиьовано 12.09.2018

прийнята до друку 26.09.2018

\section{ПОЕЛЕМЕНТНА ДЕКОМПОЗИЦІЯ АПОСТЕРІОРНОГО ОЦНЮВАЧА ПОХИБКИ НА ОСНОВІ КОНТРОЛЬНОГО РОЗВ'ЯЗКУ ДЛЯ НР- АДАПТИВНИХ СХЕМ МЕТОДУ СКІНЧЕННИХ ЕЛЕМЕНТІВ}

\section{Р. Дреботій ${ }^{1}$, Г. Шинкаренко ${ }^{1,2}$}

${ }^{1}$ Львівський наиіональний університет імені Івана Франка, вул. Університетська, 1, Львів, 79000, е-mail: roman.drebotiy@gmail.com

${ }^{2}$ Політехніка Опольська, Ополе, Польща, е-таil: h.shynkarenko@po.opole.pl

Розглянуто питання ефективного обчислення апостеріорного оцінювача похибки на основі контрольного розв'язку. Доведено, що квадрат глобального оцінювача апроксимації методу скінченних елементів (МСЕ) можна подати сумою квадратів локальних індикаторів похибки кожного елемента сітки. Отримана властивість $є$ наслідком доведеного загальнішого факту. Нехай на області визначення крайової задачі $\Omega$ задано кусково-поліноміальний простір апроксимацій МСЕ високого порядку $X_{h, p}(\Omega)$, та для довільного інтервалу $D=(\alpha, \beta) \subset \Omega$ визначено оператор ортогонального проектування $\prod_{h, p}^{D}: H^{1}(D) \rightarrow X_{h, p}(D)$, $X_{h, p}(D)=\left\{v\left|\exists u \in X_{h, p}(\Omega): v=u\right|_{D}\right\}$ стосовно напівнорми $|\cdot|_{H^{1}(D)}$, то для довільної функції $w \in H^{1}(\Omega)$ справджується така рівність:

$$
\left|w-\prod_{h, p}^{\Omega} w\right|_{H^{1}(\Omega)}^{2}=\sum_{K}\left|w-\prod_{h, p}^{K} w\right|_{H^{1}(K)}^{2},
$$

де сума береться по всіх елементах $K$ сітки. На цій підставі після обчислення контрольного розв'язку $u_{\mathbf{h} / 2, \mathbf{p}+1}$ будується апостеріорний оцінювач похибки апроксимації МСЕ у вигляді $\tilde{\eta}_{D}=\left|u_{\mathbf{h} / 2, \mathbf{p}+1}-\prod_{h, p}^{D} u_{\mathbf{h} / 2, \mathbf{p}+1}\right|_{H^{1}(D)}$. Основний результат - доведення рівності

$$
\tilde{\eta}_{\Omega}^{2}=\sum_{K} \tilde{\eta}_{K}^{2}
$$


R. Drebotiy, H. Shynkarenko

яка визначає важливий зв'язок між глобальним апостеріорним оцінювачем похибки $\tilde{\eta}_{\Omega}$ і його локальними індикаторами $\tilde{\eta}_{K}$. На додаток до цього теоретичного підгрунтя $h p$-адаптивної схеми МCE, наведено також ефективну схему обчислення розподілу локальних індикаторів $\tilde{\eta}_{K}$ із використанням базисів Лобатто.

Ключові слова: метод скінченних елементів, метод Гальоркіна, ортогональна проекція, базис Лобатто, функція Гріна, $h p$-адаптивність, апостеріорний оцінювач похибки, коректна задача, крайова задача дифузії-адвекції-реакції, контрольний розв'язок. 